\title{
Early Systemic Inflammatory Response to Drug-Eluting Stents Implantation: The Heart of the Difference?
}

\author{
Editorial to: "Comparison of Changes in Early Inflammatory Markers \\ Between Sirolimus- and Paclitaxel-Eluting Stent Implantation" by Li et al.
}

\author{
Nuno M. Pires $\cdot$ J. Wouter Jukema
}

Published online: 19 December 2008

(C) The Author(s) 2008. This article is published with open access at Springerlink.com

Percutaneous coronary intervention (PCI) is the main treatment for the revascularization of coronary arteries in patients with coronary artery disease. Intracoronary stent deployment causes arterial wall trauma which elicits a local inflammatory wound-healing response to mechanical injury leading to an increase of inflammatory mediators in the target coronary artery segment [1]. Consequently, an early systemic inflammatory response is triggered, as observed by an almost immediate rise (within minutes after PCI) in systemic inflammatory markers, such as interleukin (IL)-6, tumor necrosis factor-alpha (TNF- $\alpha$ ) and interferon-gamma $($ IFN- $\gamma)$. The production of acute phase reactants in the liver is stimulated, like C-reactive protein (CRP) and serum amyloid A protein (SAA), which rapidly increase in the circulation and which may directly amplify the local response to the inflammatory stimulus $[2,3]$. Furthermore, coronary stenting in patients with stable angina causes an elevated systemic inflammatory response compared with patients treated with angioplasty only [4]. The relationship of the systemic inflammatory response and restenosis outcome is still unclear. The majority of the studies show a correlation between (early) post-PCI systemic inflammatory markers and restenosis outcome [4]. Nonetheless, some studies report no association $[5,6]$. Several factors may contribute to this discrepancy. First, differences in baseline

\footnotetext{
N. M. Pires $\cdot$ J. W. Jukema $(\bowtie)$

Department of Cardiology, Leiden University Medical Centre, PO Box 9600, 2300 RC Leiden, The Netherlands

e-mail: j.w.jukema@lumc.nl

Present address:

N. M. Pires

Department of Research and Development,

BIAL-Portela \& Co S.A.,

À Av. da Siderurgia Nacional,

4745-457 S. Mamede do Coronado, Portugal
}

demographic, clinical and lesion characteristics may affect the inflammatory response and, therefore, the clinical prognosis. More complex lesions and/or lesions presenting high inflammatory infiltrates may show hypersensitivity to stent implantation leading to a higher inflammatory reaction. Second, inflammatory mediators have different half-lives (e.g., IL- $6 \approx 4 \mathrm{~h}$; CRP and SAA $\approx 19 \mathrm{~h}$ ) and measurement in a certain time course may not correspond to their highest peak value and not detect differences in concentrations between groups. Third, the widespread use of statins, glycoprotein IIb/IIIa antagonists, and clopidogrel may attenuate the systemic inflammatory response to PCI and mask the predictive association between systemic inflammatory values and clinical outcome. On the whole, nowadays it is considered that inflammation plays an important role after PCI with regard to restenosis [7], and this is strengthened by the fact that polymorphisms in genes coding for inflammatory proteins, e.g. TNF- $\alpha$, IL-10, caspase-1 and colony-stimulating factor 2 (CSF2) have been shown to be associated and causally involved in (clinical) restenosis $[2,8-10]$.

The introduction of drug-eluting stents (DES) in clinical practice was a milestone in the history of interventional cardiology. The two initially main worldwide available DES, i.e. Sirolimus- (SES, Cypher ${ }^{\mathrm{TM}}$ ) and Paclitaxeleluting (PES, TAXUS ${ }^{\mathrm{TM}}$ ) stents, reduce restenosis and target-vessel revascularization rate as compared to baremetal stents (BMS) [11-13]. Putative differences in terms of early systemic inflammatory response among patients treated with DES versus BMS have been put forward as a plausible explanation for the DES superiority. Literature associates DES either with a decrease $[14,15]$ or no effect $[16,17]$ in the early systemic inflammatory response compared to BMS. The reasons for these unclear results are unknown, but the same limitations as described above 
for BMS may apply for DES. Head-to-head comparison between SES and PES continues to absorb the attention of the interventional cardiology world. There is accumulating evidence that SES might in some respects be clinically better than PES [18]. Thus, can differences in terms of early systemic inflammatory response among patients implanted with different types of DES relate with the apparent SES superiority? To answer this question one needs to review (1) the pivotal phases of restenosis development and (2) the mechanism(s)-of-action of the pharmacological agent of each DES. Neointimal hyperplasia is the main cause of instent restenosis and can be defined in three pivotal characteristic phases: inflammation, granulation and remodeling. The major events in the temporal sequence of restenosis are platelet aggregation, inflammatory cell infiltration, release of growth factors, medial smooth muscle cell modulation and proliferation, proteoglycan deposition and extracellular remodeling. DES pharmacological active compounds may act on one (or more) of these key biological processes allowing localized delivery of the biological active agent directly to the target site of stent placement. Sirolimus (rapamycin) is an anti-inflammatory, immunosuppressant, antiproliferative and antimigratory agent, whereas paclitaxel is primarily a potent antiproliferative and antimigratory compound [19]. Moreover, one must keep in mind that first generation DES, like SES Cypher $^{\mathrm{TM}}$ and PES TAXUSTM, are three-part component systems, i.e. drug-polymer coating-stent, and that the drug may not be the only player when comparing both DES [13].

In the current issue of the Journal, Li et al. [20] assessed the early systemic inflammatory response after SES and PES ( $n=16$, respectively) implantation and its relationship with clinical outcome in patients with single-vessel disease in a prospective randomized manner. Peripheral blood samples were taken before PCI, 24 and $72 \mathrm{~h}$ after stenting and plasma concentrations of CRP and IL-6 were determined. Clinical and angiographic follow-up were performed at 8-months after stenting. The present study shows that implantation of both types of DES induce an acute inflammatory response, where SES implantation results in lower inflammatory responses compared with PES implantation. This seems to be of clinical relevance since this difference was associated with the degree of restenosis at 8-months follow-up. Namely, eight months clinical outcome data showed a significantly higher in-stent and in-segment late loss in the PES than in the SES group. Thus, the present study is particularly interesting because it is the first to demonstrate that patients undergoing SES implantation have a lower increase in early systemic inflammatory markers, as assessed by CRP and IL-6 plasma concentrations, after PCI as compared to PES. The postPCI lower "systemic inflammation" of SES increases the accumulating body of evidences that SES may be superior to PES in vascular healing upon PCI insult which may be associated with better clinical outcomes [18, 21, 22].

The possible association between systemic inflammatory markers and DES-associated differences has been assessed earlier. Kim and coworkers [23] performed PCI in patients (SES, $n=29$; PES, $n=17$ ) who had clinically consistent stable angina pectoris, single-vessel disease using a single coronary stent. Peripheral blood samples were obtained immediately before PCI and at $48 \mathrm{~h}, 72 \mathrm{~h}$, and 2 weeks after the procedure. There was no significant difference in CRP levels between the SES and PES at any time point studied. Likewise, Gaspardone et al. [24] evaluated patients with stable coronary artery disease who underwent successful single-vessel/lesion coronary artery stenting. SES were deployed in 30 patients and PES in 61. Venous blood samples were obtained at baseline and 24 , and $4 \mathrm{~h}$ after the procedure for CRP levels determination. The acute postprocedural systemic inflammatory response induced by SES and PES was similar. The incidence of clinical events and angiographic in-stent restenosis at 12-month follow-up was comparable in both groups. A recent publication by Kang and colleagues [25] compared the degree of systemic inflammation and its relationship to the angiographic outcomes after SES $(n=38)$ and PES $(n=41)$ implantation in a prospective, randomized trial. Patients had clinically consistent stable angina pectoris, single de novo target lesions of a native coronary artery that could be covered by a single stent. CRP and IL-6 levels were determined before and at 24, $72 \mathrm{~h}$, and 4 weeks after the PCI. There was no significant difference between the two groups in any of the CRP or IL-6 measurements. At 9-months follow-up, the late lumen loss, neointimal hyperplasia volume and the percent luminal reduction were significantly higher in the PES group than in the SES group. The divergences from the study by Li et al. [20] and the latter are unknown. Nonetheless, differences in CRP and IL-6 values at baseline and patient/lesion characteristics may reflect different inflammatory status in the different small patient cohorts which may mask modest increases in these systemic inflammatory markers upon PCI and could account for the different outcomes. It is remarkable that although there are currently numerous DES on the market, with different compounds eluted, there is surprisingly little data with regard to (vascular) biology effect, although it is becoming now more and more clear that not all DES are the same, neither with regard to efficacy nor with regard to side effects.

In conclusion, the association between DES use and systemic inflammation is still controversial. Therefore, it is still early to associate the benefits conferred by SES and a lower induction of early systemic inflammation factors. However, the study by $\mathrm{Li}$ et al. [20] provides evidences for further evaluation in larger patient populations with longerterm follow-up. Further investigations of factors that 
determine the inflammatory response to PCI are needed, for instance the role of genetic variation of inflammatory markers with PCI.

Open Access This article is distributed under the terms of the Creative Commons Attribution Noncommercial License which permits any noncommercial use, distribution, and reproduction in any medium, provided the original author(s) and source are credited.

\section{References}

1. Welt FG, Rogers C. Inflammation and restenosis in the stent era. Arterioscler Thromb Vasc Biol. 2002;22:1769-76.

2. Monraats PS, Pires NM, Schepers A, et al. Tumor necrosis factoralpha plays an important role in restenosis development. FASEB J. 2005;19:1998-2004.

3. Li JJ, Li J, Nan JL, et al. Coronary restenotic reduction of drugeluting stenting may be due to its anti-inflammatory effects. Med Hypotheses. 2007;69:1004-9.

4. Saleh N, Svane B, Jensen J, Hansson LO, Nordin M, Tornvall P. Stent implantation, but not pathogen burden, is associated with plasma C-reactive protein and interleukin- 6 concentrations after percutaneous coronary intervention in patients with stable angina pectoris. Am Heart J. 2005;149:876-82.

5. Segev A, Kassam S, Buller CE, et al. Pre-procedural plasma levels of C-reactive protein and interleukin- 6 do not predict late coronary angiographic restenosis after elective stenting. Eur Heart J. 2004;25:1029-35.

6. Gomma AH, Hirschfield GM, Gallimore JR Jr, Lowe GD, Pepys MB, Fox KM. Preprocedural inflammatory markers do not predict restenosis after successful coronary stenting. Am Heart J. 2004; 147:1071-7.

7. Agema WR, Jukema JW, Pimstone SN, Kastelein JJ. Genetic aspects of restenosis after percutaneous coronary interventions: towards more tailored therapy. Eur Heart J. 2001;22:2058-74.

8. Monraats PS, Pires NM, Agema WR, et al. Genetic inflammatory factors predict restenosis after percutaneous coronary interventions. Circulation 2005;112:2417-25.

9. Monraats PS, Kurreeman FA, Pons D, et al. Interleukin 10: a new risk marker for the development of restenosis after percutaneous coronary intervention. Genes Immun. 2007;8:44-50.

10. Monraats PS, de Vries F, de Jong LW, et al. Inflammation and apoptosis genes and the risk of restenosis after percutaneous coronary intervention. Pharmacogenet Genomics. 2006;16:747-54.
11. Moses JW, Leon MB, Popma JJ, et al. Sirolimus-eluting stents versus standard stents in patients with stenosis in a native coronary artery. N Engl J Med. 2003;349:1315-23.

12. Stone GW, Ellis SG, Cox DA, et al. A polymer-based, paclitaxeleluting stent in patients with coronary artery disease. $\mathrm{N}$ Engl J Med. 2004;350:221-31.

13. van der Hoeven BL, Pires NM, Warda HM, et al. Drug-eluting stents: results, promises and problems. Int J Cardiol. 2005;99:9-17.

14. Gibson CM, Karmpaliotis D, Kosmidou I, TIMI Study Group, et al. Comparison of effects of bare metal versus drug-eluting stent implantation on biomarker levels following percutaneous coronary intervention for non-ST-elevation acute coronary syndrome. Am J Cardiol. 2006;97:1473-7.

15. Li JJ, Qin XW, Yang XC, et al. Randomized comparison of early inflammatory response after sirolimus-eluting stent vs bare metal stent implantation in native coronary lesions. Clin Chim Acta. 2008;396:38-42.

16. Klitkou J, Jensen LO, Hansen HS, Thayssen P. High sensitive Creactive protein and interleukin 6 are not related to neointimal hyperplasia in paclitaxel eluting stents or bare metal stents. An intravascular ultrasound study. Int J Cardiol. 2007;119:114-6.

17. Gogo PB Jr, Schneider DJ, Watkins MW, Terrien EF, Sobel BE, Dauerman HL. Systemic inflammation after drug-eluting stent placement. J Thromb Thrombolysis. 2005;19:87-92.

18. Stettler C, Wandel S, Allemann S, et al. Outcomes associated with drug-eluting and bare-metal stents: a collaborative network metaanalysis. Lancet 2007;370:937-48.

19. Bennett MR. In-stent stenosis: pathology and implications for the development of drug eluting stents. Heart. 2003;89:218-24.

20. Li JJ, Yan HB, Xiang XP, et al. Comparison of changes in early inflammatory markers between sirolimus-and paclitaxel-eluting stent implantation. Cardiovasc Drugs Ther. 2009;23 (this issue).

21. Pires NM, Eefting D, de Vries MR, Quax PH, Jukema JW. Sirolimus and paclitaxel provoke different vascular pathological responses after local delivery in a murine model for restenosis on underlying atherosclerotic arteries. Heart 2007;93:922-7.

22. Finn AV, Kolodgie FD, Harnek J, et al. Differential response of delayed healing and persistent inflammation at sites of overlapping sirolimus- or paclitaxel-eluting stents. Circulation 2005;112:270-8.

23. Kim JY, Ko YG, Shim JY, et al. Comparison of effects of drugeluting stents versus bare metal stents on plasma C-reactive protein levels. Am J Cardiol. 2005;96:1384-8.

24. Gaspardone A, Versaci F, Tomai F, et al. C-reactive protein, clinical outcome, and restenosis rates after implantation of different drug-eluting stents. Am J Cardiol. 2006;97:1311-6.

25. Kang WC, Moon CI, Ahn TH, Shin EK. Comparison of inflammatory markers and angiographic outcomes after implantation of rapamycin and paclitaxel-eluting stents. Heart. 2008. doi:10.1136/hrt.2008.153114 